\title{
Article
}

\section{Quantitative Breast Density in Contrast-Enhanced Mammography}

\author{
Gisella Gennaro ${ }^{1, *(\mathbb{D}}$, Melissa L. Hill ${ }^{2} \mathbb{D}$, Elisabetta Bezzon ${ }^{1}$ and Francesca Caumo $^{1}$ \\ 1 Breast Radiology Department, Veneto Institute of Oncology (IRCCS), 35128 Padua, Italy; \\ elisabetta.bezzon@iov.veneto.it (E.B.); francesca.caumo@iov.veneto.it (F.C.) \\ 2 Volpara Health Technologies Ltd., Wellington 6011, New Zealand; Melissa.Hill@volparasolutions.com \\ * Correspondence: gisella.gennaro@iov.veneto.it
}

Citation: Gennaro, G.; Hill, M.L.; Bezzon, E.; Caumo, F. Quantitative Breast Density in Contrast-Enhanced Mammography. J. Clin. Med. 2021, 10, 3309. https://doi.org/10.3390/ jcm10153309

Academic Editor: Wendy Ingman

Received: 18 June 2021

Accepted: 22 July 2021

Published: 27 July 2021

Publisher's Note: MDPI stays neutral with regard to jurisdictional claims in published maps and institutional affiliations.

Copyright: (c) 2021 by the authors. Licensee MDPI, Basel, Switzerland. This article is an open access article distributed under the terms and conditions of the Creative Commons Attribution (CC BY) license (https:// creativecommons.org/licenses/by/ $4.0 /)$.

\begin{abstract}
Contrast-enhanced mammography (CEM) demonstrates a potential role in personalized screening models, in particular for women at increased risk and women with dense breasts. In this study, volumetric breast density (VBD) measured in CEM images was compared with VBD obtained from digital mammography (DM) or tomosynthesis (DBT) images. A total of 150 women who underwent CEM between March 2019 and December 2020, having at least a DM/DBT study performed before/after CEM, were included. Low-energy CEM (LE-CEM) and DM/DBT images were processed with automatic software to obtain the VBD. VBDs from the paired datasets were compared by Wilcoxon tests. A multivariate regression model was applied to analyze the relationship between VBD differences and multiple independent variables certainly or potentially affecting VBD. Median VBD was comparable for LE-CEM and DM/DBT (12.73\% vs. $12.39 \%)$, not evidencing any statistically significant difference $(p=0.5855)$. VBD differences between LE-CEM and DM were associated with significant differences of glandular volume, breast thickness, compression force and pressure, contact area, and nipple-to-posterior-edge distance, i.e., variables reflecting differences in breast positioning (coefficient of determination 0.6023; multiple correlation coefficient 0.7761 ). Volumetric breast density was obtained from low-energy contrast-enhanced spectral mammography and was not significantly different from volumetric breast density measured from standard mammograms.
\end{abstract}

Keywords: breast density; contrast-enhanced mammography; mammography; tomosynthesis

\section{Introduction}

The term "breast density" indicates the proportion of fibroglandular to fatty breast tissue that can be derived from mammography imaging. It has been proven that the clinical performance of mammography screening decreases as breast density increases, limiting the cancer detection rate while increasing the number of interval cancers [1,2]. Furthermore, breast density has gained increasing attention as a breast cancer risk factor $[3,4]$, and is considered a potential individual biomarker to be included in breast cancer predicting models [5-9]. Due to this twofold role of breast density as masking and risk factor, there is a strong debate to change the "one fits all" mammography screening model into "personalized" screening models, i.e., screening programs including supplemental imaging for women with dense breasts or at increased risk for breast cancer [10-12].

Breast density can be evaluated using either human- or computer-based methods. Human-derived breast density is usually assessed by means of categorical variables, for instance, BI-RADS breast density [13], but is unavoidably affected by inter- and intra-observer variability $[14,15]$. There are several computer-based methods using semi-automatic or fully automatic algorithms, capable of computing breast density as a percentage of breast area or breast volume [16-18]. Volumetric breast density (VBD), i.e., the percentage volume of fibroglandular tissue in the whole breast volume as computed by automatic software tools measured from digital mammograms, has been included in statistical models used to estimate individuals' risk of breast cancer $[9,19]$. Mammography is progressively being 
replaced by digital breast tomosynthesis (DBT); therefore, the same tools have been adapted to calculate VBD from tomosynthesis projection images [20].

Contrast-enhanced mammography (CEM, also called contrast-enhanced digital mammography, CEDM, or contrast-enhanced spectral mammography, CESM) is a dual-energy subtraction technique [21-23] applied to breast imaging [24-26], which has already produced initial results in screening contexts [27-31], showing its potential in personalized screening models [32,33]. In CEM, a pair of low-energy (LE) and high-energy (HE) images are acquired after contrast administration and used to construct the final "subtraction" image. The LE-CEM image is used to derive the morphological information, as for a standard mammogram, while the subtraction image provides functional information enhancements in areas of contrast uptake by possible breast lesions [24-26]. The prospective of using CEM as a detection tool requires that breast density can be obtained directly from CEM images. In this study, volumetric breast densities measured from LE-CEM images obtained within a study population of women at increased breast cancer risk were compared with those measured from mammography or tomosynthesis acquired before or after the CEM exam. The purpose of the study was to determine whether quantitative breast density derived from LE-CEM can be successfully used to feed breast cancer risk models within personalized screening protocols.

\section{Materials and Methods}

\subsection{Study Design and Population}

This observational cohort study (single-center) was approved by the institutional Ethics Committee. The study population included women enrolled from March 2019 to December 2020 in a prospective clinical trial (CE IOV \#2017/92) comparing the clinical performance of CEM with breast MRI in a population of 300-500 women at intermediate and high risk for breast cancer. Signed informed consent, together with a questionnaire to gather the information required by the Tyrer-Cuzick breast cancer risk model, was obtained from all women enrolled in the prospective trial. For women without known BRCA1 or BRCA2 mutations, the lifetime risk was calculated using IBIS free software which implements v. 8.0 of the Tyrer-Cuzick model [34]; according to the NICE Guideline on familial breast cancer, enrolled women were classified at high risk for breast cancer if their lifetime risk was above $30 \%$, and at intermediate risk if their lifetime risk was between $17 \%$ and $30 \%$ [35].

Subject selection for this observational study was exclusively based on the availability of mammography or DBT acquired before or after CEM. A total of 150 women with previous/subsequent mammography or DBT were used in this analysis.

\subsection{CEM and Mammography/Tomosynthesis Imaging}

Contrast-enhanced mammography was performed by a GE Senographe Pristina unit (GE Healthcare, Milwaukee Wis) after injection of a $1.5 \mathrm{~mL} / \mathrm{kg}$ iodinated contrast agent (GE Omnipaque 350) using an automatic injector $(3.0 \mathrm{~mL} / \mathrm{s})$. For pre-menopausal or peri-menopausal women, the examination was timed according to the phase of the woman's menstrual cycle to minimize potential MRI false positives and possible background parenchymal enhancement. A two-view (cranio-caudal, CC, and medio-lateral oblique, MLO) bilateral examination was performed, starting two minutes after the contrast agent injection. For each mammography view, an image pair was acquired: (1) a low-energy image (LE-CEM) obtained using the same spectra as used for a standard mammography, such that most x-ray photons had energies below the absorption peak of the contrast agent (33.2 keV for iodinated contrast); (2) an HE image (HE-CEM) using copper filtration and tube voltage so that the resulting spectrum included photons mostly above the iodine k-edge. As previously mentioned, the LE-image and a contrast-enhanced subtraction image obtained from recombining LE-CEM and HE-CEM were used for diagnosis [24-26]. 
The subtracted CEM images were visually assessed by an experienced radiologist for contrast agent uptake in the normal tissue, or background parenchymal enhancement (BPE), and assigned one of four categories: minimal, mild, moderate, or marked [36].

The DM/DBT examinations were collected from among the conventional exams that were closest in time to the acquisition date of the CEM study. This may have been prior to or following the CEM exam date. Mammography examinations were acquired by one of the following digital units: GE Senographe DS, GE Senographe Essential, GE Senographe Pristina (the same equipment used for CEM), Hologic Selenia Dimensions, IMS Giotto Image 3DL, and Siemens Mammomat Inspiration. Tomosynthesis examinations were obtained either by GE Senographe Pristina or by Hologic Selenia Dimensions.

\subsection{Breast Density}

In this study, VBD was calculated by Volpara v. 1.5.5.1 (Volpara Health Ltd., Wellington, New Zealand) in a research mode to process CEM images. The Volpara algorithm uses a model of the physics of digital mammography to work backwards from the unprocessed image pixel value to the amounts of fibroglandular and adipose tissues that would result in the measured X-ray attenuation at each detector element location. The total breast volume is generated using the compressed breast thickness reported in the image DICOM header and a model for the shape of the breast. Using this estimated breast volume and the fibroglandular tissue volume derived from the X-ray attenuation, the VBD value (fibroglandular tissue volume/volume of breast) was calculated [17]. For CEM examinations, VBD computing was limited to the LE images. To help explain potential sources of density variability, other parameters studied for their potential association with VBD are breast thickness and compression force (both obtained from the image DICOM header), area of the compression paddle in contact with the breast [37], distance between the nipple and the posterior-edge (both determined by image analysis) [38], compression pressure calculated as the ratio between compression force and contact area, and mean glandular dose (MGD) obtained by applying the dosimetry model proposed by Dance and colleagues [39-41].

\subsection{Statistical Analysis}

VBD values obtained from LE-CEM and DM/DBT paired views were compared using a two-tailed Wilcoxon test. $p<0.05$ was considered statistically significant. The same test was applied to any other variable listed above certainly or potentially affecting VBD values. Correlations between VBD measured from LE-CEM views and VBD measured from previous/subsequent DM/DBT views were evaluated by estimating the Spearman correlation coefficient, whereas the level of agreement between the two VBD datasets was explored thorough Bland-Altman plots. The same analysis (correlation and BlandAltman) was performed for each patient case, after having averaged paired VBD values from available views (CC and MLO) for the two datasets.

Finally, after having obtained two paired per-patient datasets by averaging per-view VBDs and any other considered variable, the absolute difference was calculated between mean VBD obtained from CEM and previous/subsequent DM/DBT, as well as between any mean differences between all the other variables. A multiple regression model was then applied to analyze the relationship between the dependent variable "VBD difference" and the differences between any other variable considered independent. The regression model was weighted for $1 /$ (VBD difference variance) to correct for heteroscedasticity.

Per-case VBD difference was also evaluated as a function of BPE assessed from CEM. VBD differences between the two subgroups showing minimal or mild BPE and moderate or marked BPE were compared with Mann-Whitney tests for independent samples, using the same 0.05 significance level.

Statistical analysis was performed using MedCalc ${ }^{\circledR}$ Statistical Software version 19.7 (MedCalc Software Ltd., Ostend, Belgium). 


\section{Results}

\subsection{Study Population}

Volumetric breast densities from 150 CEM examinations were compared with digital mammography or tomosynthesis performed either before or after CEM. On average, prior DM/DBT data were obtained 10.8 months before or after the CEM examination; the median time interval was 12 months, and $91 \%$ of cases (134/150) had a mammography or tomosynthesis \pm 15 months before/after CEM.

Table 1 shows the characteristics of the study population, including age, menopausal status, risk category, and breast density category.

Table 1. Characteristics of study population.

\begin{tabular}{|c|c|c|}
\hline Characteristic & Subgroup & Values \\
\hline Number of women & / & 150 \\
\hline \multirow{4}{*}{ Age (years) } & mean $\pm S D$ & $51.0 \pm 8.8$ \\
\hline & median & 51 \\
\hline & range & $(35-76)$ \\
\hline & Premenopausal & $68(45.33 \%)$ \\
\hline \multirow[t]{3}{*}{ Menopausal status } & Perimenopausal & $14(9.33 \%)$ \\
\hline & Postmenopausal & $68(45.33 \%)$ \\
\hline & BRCA1 $^{1}$ & $30(20.00 \%)$ \\
\hline \multirow{4}{*}{ Risk category } & $\mathrm{BRCA} 2^{2}$ & $36(24.00 \%)$ \\
\hline & $\mathrm{HIGH}^{3}$ & $65(41.33 \%)$ \\
\hline & INTERMEDIATE ${ }^{4}$ & $22(14.67 \%)$ \\
\hline & Predominantly fatty (A) & $9(6.00 \%)$ \\
\hline \multirow{4}{*}{ BI-RADS breast density ${ }^{5}$} & Scattered fibroglandular (B) & $27(18.00 \%)$ \\
\hline & Heterogeneously dense (C) & $55(36.67 \%)$ \\
\hline & Extremely dense (D) & $59(39.33 \%)$ \\
\hline & Minimal & $65(43.33 \%)$ \\
\hline \multirow{3}{*}{$\begin{array}{c}\text { Background parenchymal } \\
\text { enhancement (BPE) }\end{array}$} & Mild & $44(29.33 \%)$ \\
\hline & Moderate & $38(25.33 \%)$ \\
\hline & Marked & $3(2.00 \%)$ \\
\hline \multirow{2}{*}{ Previous/subsequent exam } & Mammography & $120(80.00 \%)$ \\
\hline & Tomosynthesis & $30(20.00 \%)$ \\
\hline
\end{tabular}

${ }^{1}$ Women with a mutation of the BRCA1 gene; ${ }^{2}$ women with a mutation of the BRCA2 gene; ${ }^{3}$ lifetime risk $\geq 30 \%$;

${ }^{4}$ lifetime risk between $17 \%$ and $30 \% ;{ }^{5}$ BI-RADS Breast Imaging-Reporting and Data System.

The mean age was $51.0 \pm 8.8$ years, ranging between 35 and 76 years. Pre-menopausal women were $45.33 \%(68 / 150)$ of enrolled women, while the remaining $54.67 \%(82 / 150)$ were either peri- $(14 / 150=9.33 \%)$ or post-menopausal $(68 / 150=45.33 \%)$. Most of the subjects enrolled in the study were high-risk women $(128 / 150=85.33 \%) ; 44.00 \%(66 / 150)$ had proven BRCA1 or BRCA2 mutations, and $41.33 \%(62 / 150)$ had a family history of breast cancer which, together with other risk factors also including VBD, led to a lifetime risk for breast cancer of above $30 \%$. The remaining $14.67 \%$ of women $(22 / 150)$ had intermediate risk (lifetime risk between $17 \%$ and $30 \%$ ). Women included in the study population had mostly dense breasts: $76.00 \%(114 / 150)$ were classified as BI-RADS C or D, and $24.00 \%(36 / 150)$ were classified as BI-RADS A or B. Regarding the parenchymal background enhancement evaluated with CEM, $72.67 \%$ of women showed minimal or mild BPE (109/150), and 27.3\% were moderate or marked $(41 / 150)$. Previous or subsequent exams compared to CEM were $80 \%(120 / 150)$ DM and 20\% (30/150) DBT.

\subsection{Volumetric Breast Density}

Table 2 shows results from the Wilcoxon paired test for VBD and all the other considered variables measured from LE-CEM and DM/DBT paired views. 
Table 2. Comparison between CEM and DM/DBT of volumetric breast density and related variables.

\begin{tabular}{|c|c|c|c|c|c|}
\hline Variable & $\begin{array}{l}\text { LE-CEM } \\
\text { Median }\end{array}$ & $\begin{array}{l}\text { DM/DBT } \\
\text { Median }\end{array}$ & $\begin{array}{l}\text { Hodges-Lehmann } \\
\text { Median Difference }\end{array}$ & $95 \%$ CI & $p$-Value \\
\hline $\operatorname{VBD}(\%)$ & 12.73 & 12.39 & 0.075 & -0.19 to 0.34 & 0.5855 \\
\hline Breast volume $\left(\mathrm{cm}^{2}\right)$ & 508.15 & 534.57 & 25.58 & 18.94 to 32.68 & $<0.0001$ \\
\hline Glandular volume $\left(\mathrm{cm}^{2}\right)$ & 55.90 & 59.44 & 3.315 & 1.975 to 4.660 & $<0.0001$ \\
\hline Breast thickness (mm) & 47.7 & 50.0 & 2.35 & 1.90 to 2.80 & $<0.0001$ \\
\hline Compression force (N) & 102 & 85 & -15.0 & -17.5 to -12.0 & $<0.0001$ \\
\hline Compression pressure $(\mathrm{kPa})$ & 11.83 & 10.46 & 1.655 & -1.995 to 1.310 & $<0.0001$ \\
\hline Contact area $\left(\mathrm{mm}^{2}\right)$ & 8529.46 & 8311.63 & -144.14 & -222.61 to 68.77 & 0.0003 \\
\hline $\begin{array}{l}\text { Nipple distance from } \\
\text { posterior edge (mm) }\end{array}$ & 88.40 & 88.80 & 0.60 & 0.10 to 1.15 & 0.00180 \\
\hline Mean glandular dose (mGy) & 1.544 & 1.527 & -0.043 & -0.074 to -0.012 & 0.0083 \\
\hline
\end{tabular}

Median values obtained from LE-CEM and DM/DBT paired views, Hodges-Lehmann median difference and 95\% confidence intervals, and $p$-values from the Wilcoxon paired test for VBD and all available variables actually or potentially associated with VBD. CEM, contrast-enhanced mammography; DM, digital mammography; DBT, digital breast tomosynthesis; VBD, volumetric breast density.

Median VBD was comparable for LE-CEM and previous/subsequent DM/DBT $(12.73 \%$ vs. $12.39 \%)$, not evidencing any statistically significant differences $(p=0.5855)$. Conversely, median differences between any other variable pairs were statistically significant $(p<0.05)$.

Figure 1 shows the correlation plot (on the left) and the Bland-Altman plot (on the right) for VBD measured from LE-CEM and previous/subsequent DM/DBT exams, for single views (upper plots) and for individual cases, obtaining average VBD values from multiple views (bottom plots).

The correlation was strong for both per-view and per-case comparisons $(r=0.87$ and $r=0.92$, respectively). In per-case analysis, the correlation was slightly improved compared to per-view analysis because some VBD differences for specific views were attenuated by averaging across multiple views belonging to the same study. The same effect was confirmed by the Bland-Altman plot: in both per-view and per-case plots, the mean VBD difference was zero, but the limits of agreement were narrower in per-case than in per-view analysis (about $\pm 6 \%$ against $\pm 8 \%$ ). From the per-view plots, it can be observed that the largest VBD differences between LE-CEM and previous/subsequent $\mathrm{DM} / \mathrm{DBT}$ images predominantly occurred for MLO views. The heat map in the per-case regression plots shows that volumetric breast density values were mostly below $15 \%$. The VBD difference between LE-CEM and previous/subsequent DM/DBT tended to increase with breast density.

\subsection{Multiple Regression Analysis}

Least squares multiple regression (weighted for variance) using the per-case dataset showed that breast density variability between CEM and mammography/tomosynthesis was affected by all variables which can be considered to reflect differences in breast positioning, with the exclusion of breast volume. The sample case in Figure 2 shows the LE-CEM images of a woman with large fatty breasts in the upper part, and the mammograms acquired 12 months before in the lower part: there are large differences in breast volumes between the two examinations (CEM: $2634 \mathrm{~cm}^{3}$; DM: $2058 \mathrm{~cm}^{3}$; difference $576 \mathrm{~cm}^{3}$ ) associated with large differences in breast positioning (CEM mean nipple-to-posterior-edge distance: $174 \mathrm{~mm}$; DM: $156 \mathrm{~mm}$; $18 \mathrm{~mm}$ difference), not producing significant variation in volumetric breast density (CEM: $1.9 \%$; DM: $2.7 \%$ ). In contrast, the second sample case in Figure 3 shows LE-CEM images in the upper part, and the subsequent (11.5 months later) mammography of a woman with dense breasts in the lower part; mean VBD changes were from $20.1 \%$ to $30.5 \%$ because of better positioning in the second exam. In a subsequent mammography, breasts were better positioned, including about $1 \mathrm{~cm}$ more (nipple-toposterior-edge distance) compared to CEM, resulting in a larger volume of fibroglandular 
tissue $\left(136 \mathrm{~cm}^{3}\right.$ vs. $64 \mathrm{~cm}^{3}$ with CEM) and larger overall breast volume $\left(450 \mathrm{~cm}^{3}\right.$ vs. $319 \mathrm{~cm}^{3}$ with CEM).
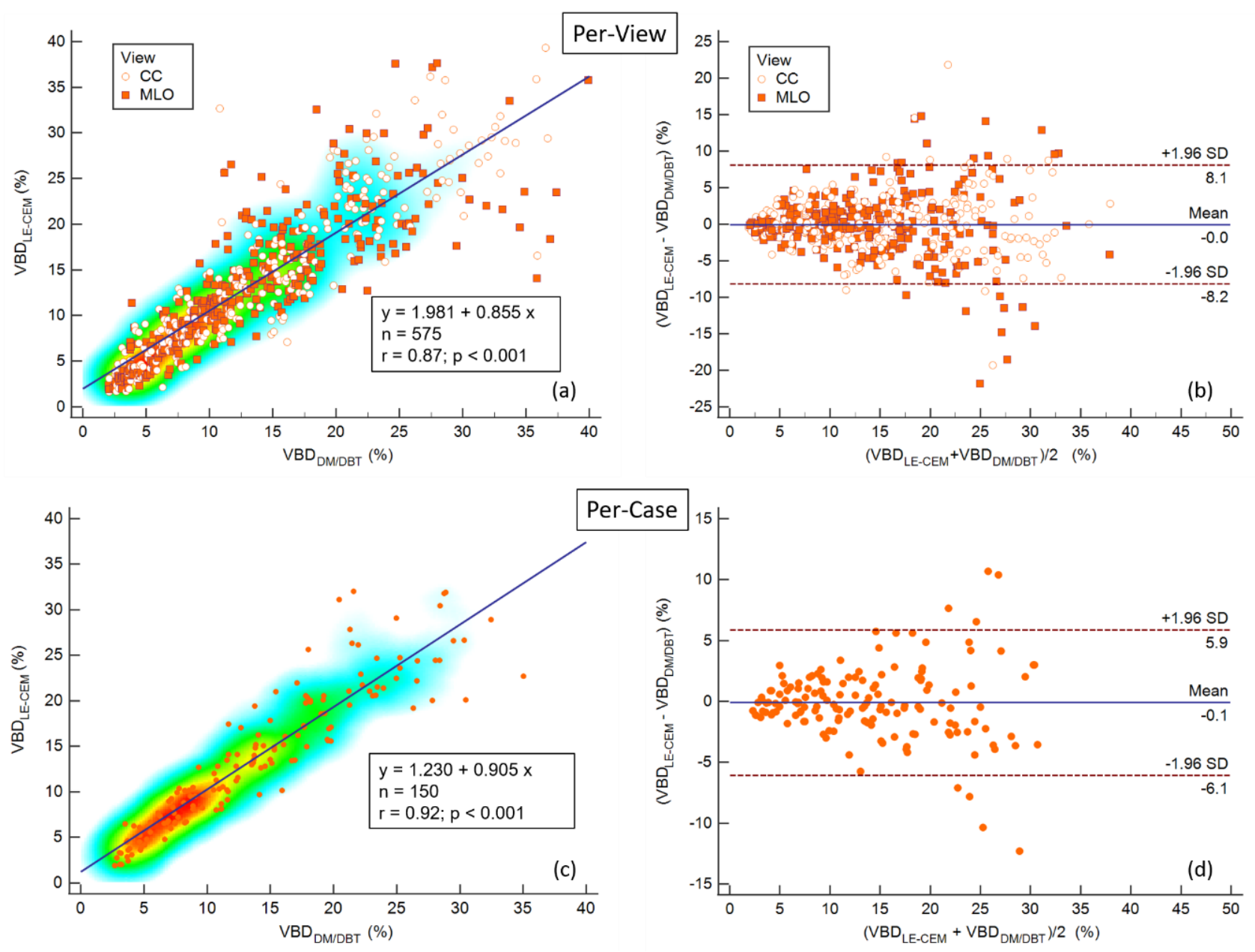

Figure 1. (a) Correlation plot of VBD measured in paired views obtained from LE-CESM and previous/subsequent $\mathrm{DM} / \mathrm{DBT}$ exams; the Pearson's correlation coefficient was $\mathrm{r}=0.87$, a reduction in correlation can be observed as VBD increases, especially for MLO views. (b) Bland-Altman plot of VBD differences between LE-CESM and previous/subsequent $\mathrm{DM} / \mathrm{DBT}$ for each paired view; the mean difference was zero, the limits of agreement were $\pm 8 \%$. (c) Correlation plot of mean VBD obtained by averaging single-view VBDs for each paired study obtained with LE-CESM and DM/DBT; the Pearson's correlation coefficient was $r=0.92$, the heat map shows that VBD values were mostly grouped below $15 \%$. (d) Bland-Altman plot of VBD differences between LE-CESM and previous/subsequent DM/DBT for each paired study; the mean difference was confirmed to be very close to zero, and the limits of agreement were reduced to $\pm 5 \%$.

As reported in Table 3, a VBD difference between LE-CEM and DM/DBT was associated with significant differences of glandular volume, breast thickness, compression pressure, nipple-to-posterior-edge distance, and to differences of compression force and contact area, while the $p$-values for breast volume and MGD difference were above 0.05 . The coefficient of determination $\left(\mathrm{R}^{2}\right)$ was 0.6023 , while the multiple correlation coefficient was 0.7761 .

Figure 4 provides a scatter plot matrix of the VBD differences and the differences between all the independent variables measured in the paired LE-CESM and DM/DBT cases. A scatter plot matrix is a grid (or matrix) of scatter plots used to visualize bivariate relationships between combinations of variables. Each scatter plot in the matrix visualizes the relationship between a pair of variables, allowing many relationships to be explored in one chart. In the upper diagonal, the distribution (histogram) of each variable difference is represented. 
The only parameter with which the VBD difference could be considered more than very weakly correlated is the difference in volume of glandular tissue $(r=0.545)$. Other correlations with moderate-to-strong relationships are recognizable between differences in breast volume and compressed breast thickness $(r=0.708)$, between breast volume differences and nipple-to-posterior-edge distance $(\mathrm{r}=0.667)$, and finally between compression pressure differences and compression force differences $(\mathrm{r}=0.880)$.

The Mann-Whitney test for independent samples applied to the subgroup of minimal or mild BPE compared with the subgroup of moderate or marked BPE did not show any statistically significant difference $(p=0.1197)$.

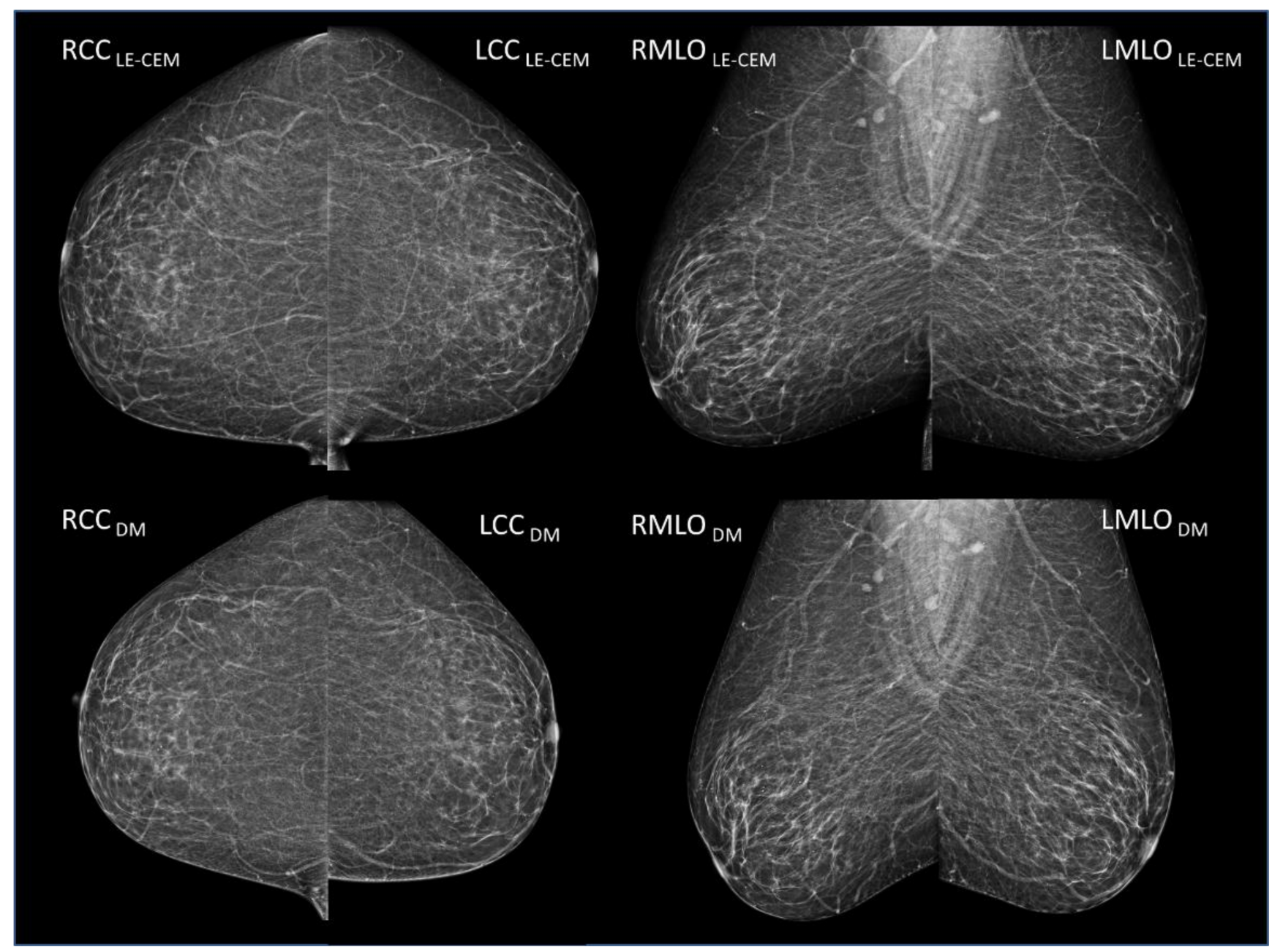

Figure 2. (Upper row) LE-CEM images of a woman with large fatty breasts. VBD: $1.9 \%$; breast volume: $2634 \mathrm{~cm}^{3}$; volume of glandular tissue: $51 \mathrm{~cm}^{3}$; breast thickness: $85 \mathrm{~mm}$; nipple-to-posterior-edge distance: $174 \mathrm{~mm}$. (Lower row) DM images acquired 12 months before the CEM exam. VBD: $2.7 \%$ : breast volume: $2058 \mathrm{~cm}^{3}$; volume of glandular tissue: $54 \mathrm{~cm}^{3}$; breast thickness: $76 \mathrm{~mm}$; nipple-to-posterior-edge distance: $155 \mathrm{~mm}$. Despite the visible difference in breast positioning, the large reduction in breast volume due to worse positioning in the DM exam did not produce a significant variation in breast density, due to the breasts being predominantly fatty. 


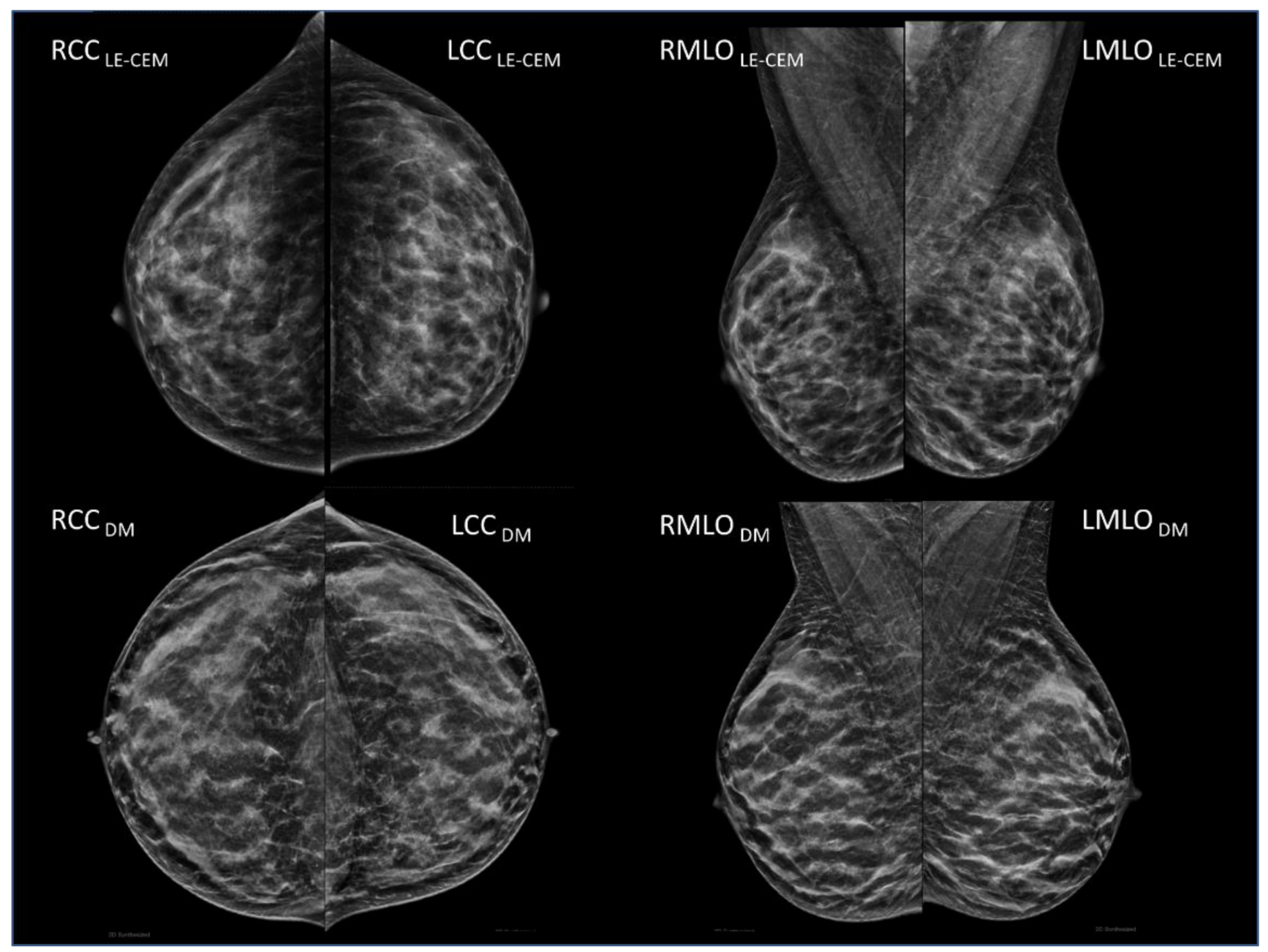

Figure 3. (Upper row) LE-CEM images of a woman with dense breasts. VBD: $20.1 \%$; breast volume: $319 \mathrm{~cm}^{3}$; volume of glandular tissue: $64 \mathrm{~cm}^{3}$; breast thickness: $32 \mathrm{~mm}$; nipple-to-posterior-edge distance: $86 \mathrm{~mm}$. (Lower row) DM images acquired 11.5 months after the CEM exam. VBD: $30.5 \%$; breast volume: $450 \mathrm{~cm}^{3}$; volume of glandular tissue: $136 \mathrm{~cm}^{3}$; breast thickness: $41 \mathrm{~mm}$; nipple-to-posterior-edge distance: $98 \mathrm{~mm}$. Breast positioning was better in the DM exam, including an additional volume of glandular tissue, leading to a significant increment in VBD.

Table 3. Coefficients of the regression equation and $p$-values resulting from the multiple regression model.

\begin{tabular}{ccc}
\hline Independent Variable Difference & Regression Coefficient & $p$-Value \\
\hline (Constant) & 0.1741 & \\
Breast volume $\left(\mathrm{cm}^{3}\right)$ & 0.005017 & 0.1311 \\
Glandular volume $\left(\mathrm{cm}^{3}\right)$ & 0.1174 & $<0.0001$ \\
Breast thickness $(\mathrm{mm})$ & -0.2748 & $<0.0001$ \\
Compression force $(\mathrm{N})$ & 0.05008 & 0.0036 \\
Compression pressure $(\mathrm{kPa})$ & -0.5031 & 0.0001 \\
Contact area $\left(\mathrm{mm}^{2}\right)$ & -0.0009143 & $<0.0001$ \\
Nipple-to-posterior-edge distance $(\mathrm{mm})$ & -0.1453 & 0.0011 \\
Mean glandular dose (mGy) & -0.1373 & 0.6684
\end{tabular}

VBD differences between LE-CEM and DM/DBT were considered the dependent variable; differences in breast volume, glandular volume, breast thickness, contact area, compression force, compression pressure, nippleto-posterior-edge distance, and mean glandular dose were included in the model as independent variables. CEM, contrast-enhanced mammography; DM, digital mammography; DBT, digital breast tomosynthesis; VBD, volumetric breast density. 


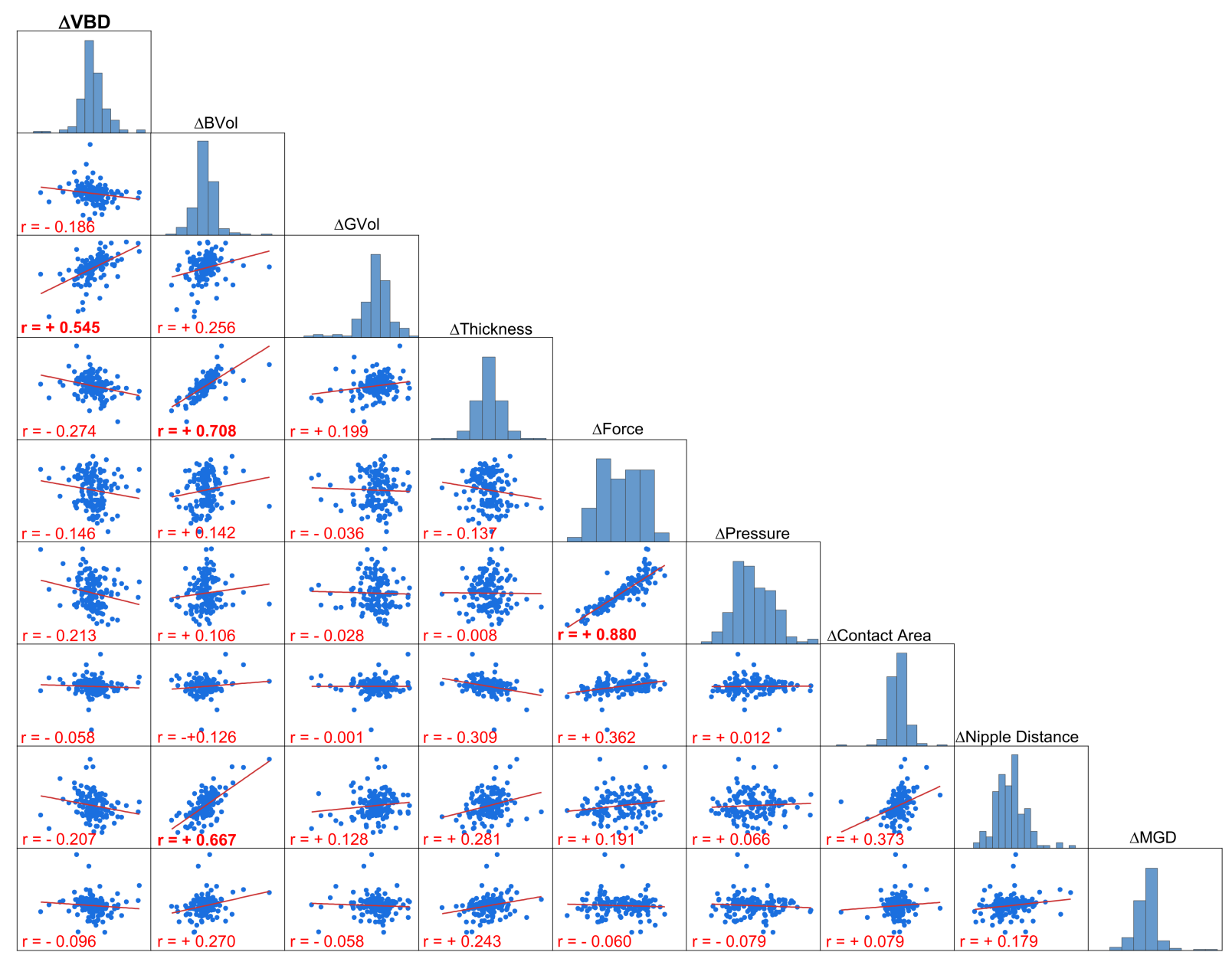

Figure 4. Scatter plot matrix of the VBD differences obtained from CEM and DM/DBT images and their relationship with all the other variable differences considered as independent in the multiple regression model: breast volume, volume of glandular tissue, breast thickness, compression force and pressure, contact area, nipple-to-posterior-edge distance, and mean glandular dose.

\section{Discussion}

The comparison between volumetric breast density measured in LE-CEM and in previous/subsequent DM or DBT images for the same patients did not find any statistically significant difference. This result was confirmed by the high correlation between the two VBD pairs for both per-view and per-case datasets, and with the Bland-Altman plots showing that the absolute differences between VBDs measured in LE-CEM and in $\mathrm{DM} / \mathrm{DBT}$ were very close to zero, with limits of agreement moving from $\pm 8 \%$ in per-view analysis to $\pm 6 \%$ in per-case analysis, respectively. This result suggests that VBD measured from LE-CEM images is comparable with VBD obtained from standard mammography or tomosynthesis images. Therefore, if CEM is used as a detection tool, VBD measured using CEM can be used for risk evaluation as if it would be obtained from mammography. This reinforces the substantial clinical equivalence between LE-CEM and mammography images, as published by Lalji and colleagues, who compared LE-CEM and DM image quality by applying EUREF clinical criteria [42].

The multiple regression model showed that VBD differences are associated with variables related to breast compression (compression force and pressure, compressed breast thickness, and contact area) and with variables related to breast positioning (volume of glandular tissue and nipple-to-posterior-edge distance). X-ray breast imaging, including mammography, tomosynthesis, and CEM requires manual breast compression and positioning by a breast radiographer; therefore, it is very difficult, despite the application of 
criteria of "correct positioning", to ensure that breast compression and positioning are the same laterality and view for consecutive exams. In other words, despite the known advantages of using quantitative tools to evaluate breast density (compared to subjective categorization affected by intra- and inter-observer variability for the same exam), radiologists should be aware that the reproducibility of breast density in two consecutive examinations can be subordinated to breast compression and positioning reproducibility. This topic was previously explored by Alonzo-Proulx et al. in a small study of repositioning the left breasts of 30 volunteers for a second CC view to evaluate the effect on measured density [43]. That study found a comparable VBD variability (between $-4.25 \%$ and $2.28 \%$ ) to that observed here, even in the context of repositioning the breast on the same day and imaging on the same equipment. Such awareness of the potential sensitivity of density measurement to breast positioning is particularly important in cases where the quantitative breast density is used as a decision-making index to drive supplemental imaging or risk assessments in personalized screening programs. Breast density has been shown to increase the accuracy of breast cancer risk models [9], although variability in breast density measures associated with changes in breast compression and positioning might have an impact on the predicted breast cancer risk. An investigation of breast positioning and compression quality is out of the scope of this work, but it is postulated that good breast positioning quality and consistent compression practices could mitigate the variability in automated density measurement, and subsequently, the impact on breast cancer risk estimates.

Apart from breast positioning changes, the only other physical means by which the quantitative density on LE-CEM could be different from DM/DBT should be related to the potential presence of contrast agents in the breast tissue, and their influence on the image pixel magnitudes. BPE assessed on the subtracted image was used here as a surrogate estimate for the amount of normal tissue contrast agent taken up. The findings demonstrated no association between BPE and VBD differences; therefore, it is estimated that the amount of iodine taken up in typical CEM produces signal intensity changes that are small enough as to not influence the density measurement method applied in this work.

The first implication of the study results is that in cases where CEM will be confirmed as a valid alternative to mammography and breast MRI in women at increased risk of breast cancer, CEM could be replaced by mammography with or without the addition of MRI (not used as a supplemental tool). For this reason, obtaining the same breast density values as standard mammography/tomosynthesis is useful and can be employed for risk assessments.

In addition to this direct implication, volumetric breast density may be a surrogate marker for response to neo-adjuvant chemotherapy (NAC), as reported by Engmann et al. (2017) [44]. Although responses to NAC can also be monitored with CEM [24-26,45], it will be of interest for future work to determine whether changes in VBD can provide independent and complementary information changes in contrast-enhancement on CEM. Furthermore, younger high-risk women who may benefit from CESM screening are also a target population for prevention strategies. Mammographic VBD and measurements of fibroglandular volume have been demonstrated as useful markers of breast density change associated with interventions that include chemoprevention [46-48], oophorectomy [49], diet [50], and weight loss [51].

This study has some limitations: the sample size was relatively small because for practical purposes, all available cases that met study criteria were included from the ancillary prospective trial comparing CEM and MRI performance among women at intermediate and high risk for breast cancer. As such, the study sample size was determined in an opportunistic manner, rather than being selected according to a power calculation. It is recommended that a larger sample be used in future work to confirm the results observed here. In addition, the inclusion of women not represented in the study population is encouraged, such as women at low risk for breast cancer. All LE-CEM images were produced by one type of equipment. If other vendor systems have different sensitivities to contrast agents, if a different injection protocol is applied, or if a substantially different compression is used, 
these results may not be applicable. Similar studies using other vendor systems are recommended. The study DM images were not obtained at the same time as the CEM images, and were often acquired using different imaging systems that are used for CEM. It is known that a woman's breast density can change over time for a variety of reasons [52]. Nevertheless, the time interval between DM and CEM examinations (mean: 11 months; median: 12 months) was short enough to assume the substantial temporal stability of breast density, at least at a population level [52]. The use of different imaging systems between DM and CEM exams may actually have a greater influence on the variability of density results. For example, it is known that a change in compression paddle type can influence the amount of tissue in the field of view [53], and the combination of machine/paddle/compression modes can influence the accuracy of compressed thickness readout [54], both of which can influence the VBD estimate accuracy [55]. Only one automated density measurement tool was used in this study, which was a research-specific version compatible with LE-CEM. At the time of writing, we are not aware of any other automated density tools available for use with CEM images, in either a research setting or otherwise. In future work, it will be interesting to evaluate other density measurement software for this application, especially to test those with alternative measurement methods to understand the importance of the approach to any potential sensitivity to the presence of contrast agent in the breast tissue.

\section{Conclusions}

In conclusion, volumetric breast density can be obtained from contrast-enhanced spectral mammography (low-energy images), and is not significantly different from volumetric breast density values measured from standard mammograms, outside the inherent uncertainty associated with breast compression and positioning. This result will become particularly helpful if contrast-enhanced mammography gains a role as a key test in the personalization of screening programs for specific populations of women.

Author Contributions: Conceptualization, G.G. and F.C.; methodology, G.G. and M.L.H.; formal analysis, G.G.; investigation, G.G. and F.C.; data curation, G.G. and E.B.; writing-original draft preparation, G.G. and F.C.; writing-review and editing, M.L.H. and E.B. All authors have read and agreed to the published version of the manuscript.

Funding: The clinical study from which the dataset used in this study was extracted received financial support by the Veneto Region, grant number RSF-2017-00000562. This study received no external funding.

Institutional Review Board Statement: The study was conducted according to the guidelines of the Declaration of Helsinki, and approved by the Ethics Committee of the Veneto Institute of Oncology (CE IOV \#2017/92; date of approval: 22 December 2017.

Informed Consent Statement: Informed consent was obtained from all subjects involved in the study.

Data Availability Statement: The data presented in this study are available on request from the corresponding author.

Acknowledgments: The authors thank Enrica Baldan for her contribution in recruiting women, and Maria Petrioli and Tiziana Masiero for their effort in the optimization of CEM examinations.

Conflicts of Interest: M.L.H. is a consultant of Volpara Health Technologies Ltd. The other authors declare no conflict of interest.

\section{References}

1. Day, N.; Warren, R. Mammographic Screening and Mammographic Patterns. Breast Cancer Res. 2000, 2, 247-251. [CrossRef]

2. Mandelson, M.T.; Oestreicher, N.; Porter, P.L.; White, D.; Finder, C.A.; Taplin, S.H.; White, E. Breast Density as a Predictor of Mammographic Detection: Comparison of Interval- and Screen-Detected Cancers. J. Natl. Cancer Inst. 2000, 92, 1081-1087. [CrossRef] [PubMed]

3. Boyd, N.F.; Martin, L.J.; Yaffe, M.J.; Minkin, S. Mammographic Density and Breast Cancer Risk: Current Understanding and Future Prospects. Breast Cancer Res. 2011, 13, 223. [CrossRef] [PubMed] 
4. Soguel, L.; Durocher, F.; Tchernof, A.; Diorio, C. Adiposity, Breast Density, and Breast Cancer Risk: Epidemiological and Biological Considerations. Eur. J. Cancer Prev. 2017, 26, 511-520. [CrossRef]

5. Posso, M.; Louro, J.; Sánchez, M.; Román, M.; Vidal, C.; Sala, M.; Baré, M.; Castells, X.; BELE Study Group. Mammographic Breast Density: How It Affects Performance Indicators in Screening Programmes? Eur. J. Radiol. 2019, 110, 81-87. [CrossRef] [PubMed]

6. Gail, M.H.; Pfeiffer, R.M. Breast Cancer Risk Model Requirements for Counseling, Prevention, and Screening. J. Natl. Cancer Inst. 2018, 110, 994-1002. [CrossRef]

7. Lee, A.; Mavaddat, N.; Wilcox, A.N.; Cunningham, A.P.; Carver, T.; Hartley, S.; Babb de Villiers, C.; Izquierdo, A.; Simard, J.; Schmidt, M.K.; et al. BOADICEA: A Comprehensive Breast Cancer Risk Prediction Model Incorporating Genetic and Nongenetic Risk Factors. Genet. Med. 2019, 21, 1708-1718. [CrossRef]

8. Tyrer, J.; Duffy, S.W.; Cuzick, J. A Breast Cancer Prediction Model Incorporating Familial and Personal Risk Factors. Stat. Med. 2004, 23, 1111-1130. [CrossRef]

9. Brentnall, A.R.; Harkness, E.F.; Astley, S.M.; Donnelly, L.S.; Stavrinos, P.; Sampson, S.; Fox, L.; Sergeant, J.C.; Harvie, M.N.; Wilson, M.; et al. Mammographic Density Adds Accuracy to Both the Tyrer-Cuzick and Gail Breast Cancer Risk Models in a Prospective UK Screening Cohort. Breast Cancer Res. 2015, 17, 147. [CrossRef]

10. Lee, C.I.; Chen, L.E.; Elmore, J.G. Risk-Based Breast Cancer Screening: Implications of Breast Density. Med. Clin. N. Am. 2017, 101, 725-741. [CrossRef]

11. Destounis, S.V.; Santacroce, A.; Arieno, A. Update on Breast Density, Risk Estimation, and Supplemental Screening. AJR Am. J. Roentgenol. 2020, 214, 296-305. [CrossRef]

12. Lian, J.; Li, K. A Review of Breast Density Implications and Breast Cancer Screening. Clin. Breast Cancer 2020, 20, 283-290. [CrossRef] [PubMed]

13. Spak, D.A.; Plaxco, J.S.; Santiago, L.; Dryden, M.J.; Dogan, B.E. BI-RADS Fifth Edition: A Summary of Changes. Diagn. Interv. Imaging 2017, 98, 179-190. [CrossRef]

14. Ciatto, S.; Houssami, N.; Apruzzese, A.; Bassetti, E.; Brancato, B.; Carozzi, F.; Catarzi, S.; Lamberini, M.P.; Marcelli, G.; Pellizzoni, R.; et al. Categorizing Breast Mammographic Density: Intra- and Interobserver Reproducibility of BI-RADS Density Categories. Breast 2005, 14, 269-275. [CrossRef]

15. Sacchetto, D.; Morra, L.; Agliozzo, S.; Bernardi, D.; Björklund, T.; Brancato, B.; Bravetti, P.; Carbonaro, L.A.; Correale, L.; Fantò, C.; et al. Mammographic Density: Comparison of Visual Assessment with Fully Automatic Calculation on a Multivendor Dataset. Eur. Radiol. 2016, 26, 175-183. [CrossRef]

16. Yaffe, M.J. Mammographic Density. Measurement of Mammographic Density. Breast Cancer Res. 2008, 10, 209. [CrossRef] [PubMed]

17. Highnam, R.; Jeffreys, M.; McCormack, V.; Warren, R.; Davey Smith, G.; Brady, M. Comparing Measurements of Breast Density. Phys. Med. Biol. 2007, 52, 5881-5895. [CrossRef]

18. Keller, B.M.; Chen, J.; Daye, D.; Conant, E.F.; Kontos, D. Preliminary Evaluation of the Publicly Available Laboratory for Breast Radiodensity Assessment (LIBRA) Software Tool: Comparison of Fully Automated Area and Volumetric Density Measures in a Case-Control Study with Digital Mammography. Breast Cancer Res. 2015, 17, 117. [CrossRef] [PubMed]

19. Gastounioti, A.; Kasi, C.D.; Scott, C.G.; Brandt, K.R.; Jensen, M.R.; Hruska, C.B.; Wu, F.F.; Norman, A.D.; Conant, E.F.; Winham, S.J.; et al. Evaluation of LIBRA Software for Fully Automated Mammographic Density Assessment in Breast Cancer Risk Prediction. Radiology 2020, 296, 24-31. [CrossRef] [PubMed]

20. Ekpo, E.U.; McEntee, M.F. Measurement of Breast Density with Digital Breast Tomosynthesis-A Systematic Review. Br. J. Radiol. 2014, 87, 20140460. [CrossRef] [PubMed]

21. Blake, G.M.; Fogelman, I. Technical Principles of Dual Energy X-Ray Absorptiometry. Semin. Nucl. Med. 1997, 27, 210-228. [CrossRef]

22. Manji, F.; Wang, J.; Norman, G.; Wang, Z.; Koff, D. Comparison of Dual Energy Subtraction Chest Radiography and Traditional Chest X-Rays in the Detection of Pulmonary Nodules. Quant. Imaging Med. Surg. 2016, 6, 1-5. [CrossRef]

23. McCollough, C.H.; Leng, S.; Yu, L.; Fletcher, J.G. Dual- and Multi-Energy CT: Principles, Technical Approaches, and Clinical Applications. Radiology 2015, 276, 637-653. [CrossRef] [PubMed]

24. Skarpathiotakis, M.; Yaffe, M.J.; Bloomquist, A.K.; Rico, D.; Muller, S.; Rick, A.; Jeunehomme, F. Development of Contrast Digital Mammography. Med. Phys. 2002, 29, 2419-2426. [CrossRef]

25. Lobbes, M.B.I.; Smidt, M.L.; Houwers, J.; Tjan-Heijnen, V.C.; Wildberger, J.E. Contrast Enhanced Mammography: Techniques, Current Results, and Potential Indications. Clin. Radiol. 2013, 68, 935-944. [CrossRef]

26. Patel, B.K.; Lobbes, M.B.I.; Lewin, J. Contrast Enhanced Spectral Mammography: A Review. Semin. Ultrasound CT MR 2018, 39, 70-79. [CrossRef]

27. Lalji, U.; Lobbes, M. Contrast-Enhanced Dual-Energy Mammography: A Promising New Imaging Tool in Breast Cancer Detection. Women's Health 2014, 10, 289-298. [CrossRef]

28. Gilbert, F.J.; Pinker-Domenig, K. Diagnosis and Staging of Breast Cancer: When and How to Use Mammography, Tomosynthesis, Ultrasound, Contrast-Enhanced Mammography, and Magnetic Resonance Imaging. In Diseases of the Chest, Breast, Heart and Vessels 2019-2022: Diagnostic and Interventional Imaging; Hodler, J., Kubik-Huch, R.A., von Schulthess, G.K., Eds.; Springer: Cham, Switzerland, 2019; ISBN 9783030111489. 
29. Lobbes, M.B.I.; Lalji, U.; Houwers, J.; Nijssen, E.C.; Nelemans, P.J.; van Roozendaal, L.; Smidt, M.L.; Heuts, E.; Wildberger, J.E. Contrast-Enhanced Spectral Mammography in Patients Referred from the Breast Cancer Screening Programme. Eur. Radiol. 2014, 24, 1668-1676. [CrossRef]

30. Houben, I.P.L.; Van de Voorde, P.; Jeukens, C.R.L.P.N.; Wildberger, J.E.; Kooreman, L.F.; Smidt, M.L.; Lobbes, M.B.I. ContrastEnhanced Spectral Mammography as Work-up Tool in Patients Recalled from Breast Cancer Screening Has Low Risks and Might Hold Clinical Benefits. Eur. J. Radiol. 2017, 94, 31-37. [CrossRef] [PubMed]

31. Mori, M.; Akashi-Tanaka, S.; Suzuki, S.; Daniels, M.I.; Watanabe, C.; Hirose, M.; Nakamura, S. Diagnostic Accuracy of ContrastEnhanced Spectral Mammography in Comparison to Conventional Full-Field Digital Mammography in a Population of Women with Dense Breasts. Breast Cancer 2017, 24, 104-110. [CrossRef] [PubMed]

32. Sorin, V.; Yagil, Y.; Yosepovich, A.; Shalmon, A.; Gotlieb, M.; Neiman, O.H.; Sklair-Levy, M. Contrast-Enhanced Spectral Mammography in Women With Intermediate Breast Cancer Risk and Dense Breasts. AJR Am. J. Roentgenol. 2018, 211, W267-W274. [CrossRef]

33. Sung, J.S.; Lebron, L.; Keating, D.; D’Alessio, D.; Comstock, C.E.; Lee, C.H.; Pike, M.C.; Ayhan, M.; Moskowitz, C.S.; Morris, E.A.; et al. Performance of Dual-Energy Contrast-Enhanced Digital Mammography for Screening Women at Increased Risk of Breast Cancer. Radiology 2019, 293, 81-88. [CrossRef] [PubMed]

34. Himes, D.O.; Root, A.E.; Gammon, A.; Luthy, K.E. Breast Cancer Risk Assessment: Calculating Lifetime Risk Using the Tyrer-Cuzick Model. J. Nurse Pract. 2016, 12, 581-592. [CrossRef]

35. National Institute for Health and Care Excellence. Familial Breast Cancer: Classification, Care and Managing Breast Cancer and Related Risks in People with a Family History of Breast Cancer; National Institute for Health and Care Excellence: London, UK, 2020; ISBN 9781473101609.

36. Branderhorst, W.; de Groot, J.E.; van Lier, M.G.J.T.B.; Highnam, R.P.; den Heeten, G.J.; Grimbergen, C.A. Technical Note: Validation of Two Methods to Determine Contact Area between Breast and Compression Paddle in Mammography. Med. Phys. 2017, 44, 4040-4044. [CrossRef] [PubMed]

37. Waade, G.G.; Danielsen, A.S.; Holen, Å.S.; Larsen, M.; Hanestad, B.; Hopland, N.-M.; Kalcheva, V.; Hofvind, S. Assessment of Breast Positioning Criteria in Mammographic Screening: Agreement between Artificial Intelligence Software and Radiographers. J. Med. Screen. 2021, 969141321998718. [CrossRef]

38. Dance, D.R.; Skinner, C.L.; Young, K.C.; Beckett, J.R.; Kotre, C.J. Additional Factors for the Estimation of Mean Glandular Breast Dose Using the UK Mammography Dosimetry Protocol. Phys. Med. Biol. 2000, 45, 3225-3240. [CrossRef]

39. Dance, D.R.; Young, K.C.; van Engen, R.E. Further Factors for the Estimation of Mean Glandular Dose Using the United Kingdom, European and IAEA Breast Dosimetry Protocols. Phys. Med. Biol. 2009, 54, 4361-4372. [CrossRef] [PubMed]

40. Dance, D.R.; Young, K.C. Estimation of Mean Glandular Dose for Contrast Enhanced Digital Mammography: Factors for Use with the UK, European and IAEA Breast Dosimetry Protocols. Phys. Med. Biol. 2014, 59, 2127-2137. [CrossRef]

41. Sogani, J.; Morris, E.A.; Kaplan, J.B.; D’Alessio, D.; Goldman, D.; Moskowitz, C.S.; Jochelson, M.S. Comparison of Background Parenchymal Enhancement at Contrast-Enhanced Spectral Mammography and Breast MR Imaging. Radiology 2017, 282, 63-73. [CrossRef]

42. Lalji, U.C.; Jeukens, C.R.L.P.N.; Houben, I.; Nelemans, P.J.; van Engen, R.E.; van Wylick, E.; Beets-Tan, R.G.H.; Wildberger, J.E.; Paulis, L.E.; Lobbes, M.B.I. Evaluation of Low-Energy Contrast-Enhanced Spectral Mammography Images by Comparing Them to Full-Field Digital Mammography Using EUREF Image Quality Criteria. Eur. Radiol. 2015, 25, 2813-2820. [CrossRef]

43. Alonzo-Proulx, O.; Mawdsley, G.E.; Patrie, J.T.; Yaffe, M.J.; Harvey, J.A. Reliability of Automated Breast Density Measurements. Radiology 2015, 275, 366-376. [CrossRef] [PubMed]

44. Engmann, N.J.; Scott, C.G.; Jensen, M.R.; Ma, L.; Brandt, K.R.; Mahmoudzadeh, A.P.; Malkov, S.; Whaley, D.H.; Hruska, C.B.; Wu, F.F.; et al. Longitudinal Changes in Volumetric Breast Density with Tamoxifen and Aromatase Inhibitors. Cancer Epidemiol. Biomark. Prev. 2017, 26, 930-937. [CrossRef]

45. Iotti, V.; Ravaioli, S.; Vacondio, R.; Coriani, C.; Caffarri, S.; Sghedoni, R.; Nitrosi, A.; Ragazzi, M.; Gasparini, E.; Masini, C.; et al. Contrast-Enhanced Spectral Mammography in Neoadjuvant Chemotherapy Monitoring: A Comparison with Breast Magnetic Resonance Imaging. Breast Cancer Res. 2017, 19, 106. [CrossRef]

46. Brentnall, A.R.; Warren, R.; Harkness, E.F.; Astley, S.M.; Wiseman, J.; Fox, J.; Fox, L.; Eriksson, M.; Hall, P.; Cuzick, J.; et al. Mammographic Density Change in a Cohort of Premenopausal Women Receiving Tamoxifen for Breast Cancer Prevention over 5 Years. Breast Cancer Res. 2020, 22, 101. [CrossRef] [PubMed]

47. Fabian, C.J.; Nye, L.; Powers, K.R.; Nydegger, J.L.; Kreutzjans, A.L.; Phillips, T.A.; Metheny, T.; Winblad, O.; Zalles, C.M.; Hagan, C.R.; et al. Effect of Bazedoxifene and Conjugated Estrogen (Duavee) on Breast Cancer Risk Biomarkers in High-Risk Women: A Pilot Study. Cancer Prev. Res. 2019, 12, 711-720. [CrossRef]

48. Manni, A.; Richie, J.P.; Schetter, S.E.; Calcagnotto, A.; Trushin, N.; Aliaga, C.; El-Bayoumy, K. Stearoyl-CoA Desaturase-1, a Novel Target of Omega-3 Fatty Acids for Reducing Breast Cancer Risk in Obese Postmenopausal Women. Eur. J. Clin. Nutr. 2017, 71, 762-765. [CrossRef] [PubMed]

49. Lecler, A.; Dunant, A.; Delaloge, S.; Wehrer, D.; Moussa, T.; Caron, O.; Balleyguier, C. Breast Tissue Density Change after Oophorectomy in BRCA Mutation Carrier Patients Using Visual and Volumetric Analysis. Br. J. Radiol. 2018, 91, 20170163. [CrossRef] [PubMed] 
50. Masala, G.; Assedi, M.; Sera, F.; Ermini, I.; Occhini, D.; Castaldo, M.; Pierpaoli, E.; Caini, S.; Bendinelli, B.; Ambrogetti, D.; et al. Can Dietary and Physical Activity Modifications Reduce Breast Density in Postmenopausal Women? The DAMA Study, a Randomized Intervention Trial in Italy. Cancer Epidemiol. Biomark. Prev. 2019, 28, 41-50. [CrossRef]

51. Vohra, N.A.; Kachare, S.D.; Vos, P.; Schroeder, B.F.; Schuth, O.; Suttle, D.; Fitzgerald, T.L.; Wong, J.H.; Verbanac, K.M. The Short-Term Effect of Weight Loss Surgery on Volumetric Breast Density and Fibroglandular Volume. Obes. Surg. 2017, 27, 1013-1023. [CrossRef] [PubMed]

52. Shia, W.-C.; Wu, H.-K.; Huang, Y.-L.; Lin, L.-S.; Chen, D.-R. Mammographic Density Distribution of Healthy Taiwanese Women and Its Naturally Decreasing Trend with Age. Sci. Rep. 2018, 8, 14937. [CrossRef] [PubMed]

53. Broeders, M.J.M.; Ten Voorde, M.; Veldkamp, W.J.H.; van Engen, R.E.; van Landsveld-Verhoeven, C.; 't Jong-Gunneman, M.N.L.; de Win, J.; Greve, K.D.; Paap, E.; den Heeten, G.J. Comparison of a Flexible versus a Rigid Breast Compression Paddle: Pain Experience, Projected Breast Area, Radiation Dose and Technical Image Quality. Eur. Radiol. 2015, 25, 821-829. [CrossRef] [PubMed]

54. Maki, A.K.; Mainprize, J.G.; Pisano, E.D.; Mawdsley, G.E.; Skarpathiotakis, M.; Yaffe, M.J. Technical Note: Volumetric Coverage in Breast Tomosynthesis Images—Phantom QC Results from the TMIST Study. Med. Phys. 2021. [CrossRef] [PubMed]

55. Lau, S.; Ng, K.H.; Abdul Aziz, Y.F. Volumetric Breast Density Measurement: Sensitivity Analysis of a Relative Physics Approach. Br. J. Radiol. 2016, 89, 20160258. [CrossRef] [PubMed] 